\title{
Normalized Shear Modulus and Damping Ratio of Soil-Rock Mixtures With Different Volumetric Block Proportions
}

\author{
Shengnian Wang ${ }^{1 *}$, Xinqun Gao ${ }^{1}$, Honglei Hui ${ }^{1}$, Wei $\mathrm{Ma}^{2}$, Chong Shi ${ }^{3}$ and Peng Zhang ${ }^{1 *}$ \\ ${ }^{1}$ College of Transportation Science and Engineering, Nanjing Tech University, Nanjing, China, ${ }^{2}$ State Key Laboratory of Frozen \\ Soil Engineering, Northwest Institute of Eco-Environment and Resources, Chinese Academy of Sciences, Lanzhou, China, \\ ${ }^{3}$ Institute of Geotechnical Engineering, Hohai University, Nanjing, China
}

\section{OPEN ACCESS}

Edited by:

Wanqing Shen,

Université de Lille, France

Reviewed by:

Lanlan Yang,

Jiangnan University, China

Kai Wu,

Southeast University, China

*Correspondence:

Shengnian Wang

shengnian.wang@njtech.edu.cn

Peng Zhang

zhangpeng-mail@njtech.edu.cn

Specialty section:

This article was submitted to Interdisciplinary Physics,

a section of the journal

Frontiers in Physics

Received: 14 July 2021

Accepted: 13 August 2021

Published: 28 September 2021

Citation:

Wang S, Gao X, Hui H, Ma W, Shi C and Zhang P (2021) Normalized Shear

Modulus and Damping Ratio of

Soil-Rock Mixtures With Different

Volumetric Block Proportions.

Front. Phys. 9:740993.

doi: 10.3389/fphy.2021.740993
The volume fraction of rock blocks plays a particularly significant role in static/dynamic shear behaviors of soil-rock mixtures (SRM). Large-scale cyclic triaxial tests for SRM with different volumetric block proportions (VBPs) were performed at different confining pressures to investigate the reduction of dynamic shear modulus $(G)$ and the increase of damping ratio $(\lambda)$. Results indicate that VBP has a significant effect on the dynamic behaviors of SRM. The higher VBP is more likely to result in a gentler reduction of $G$ and a faster increase of $\lambda$. The variations of dynamic shear modulus ratio $\left(G / G_{0}\right)$ and normalized damping ratio $\left(\lambda_{\text {nor }}\right)$ fall within relatively narrow bands but are very different with gravelly soils and sands due to VBP with particle size larger than $2 \mathrm{~mm}$. The $\mathrm{G} / \mathrm{G} 0$ and $\lambda_{\text {nor }}$ can be characterized by empirical functions about normalized shear strain amplitude $\left(\gamma_{\text {nor }}\right)$.

Keywords: soil-rock mixture, shear modulus, damping ratio, volumetric block proportion, dynamic properties

\section{INTRODUCTION}

Soil-rock mixtures (SRMs) are inhomogeneous and heterogeneous geological materials widely used in infrastructure projects such as road foundations, earth dams, and slopes [1]. However, since their mechanical and physical properties are significantly determined by the interaction and properties of rock blocks, SRM belongs to neither the category of soil nor rock [2]. Great difficulties in parameter determination represent a significant challenge in engineering practice and thus have attracted the attention of scholars from home and abroad.

Soil dynamic parameters, including dynamic shear modulus $(G)$, dynamic shear modulus ratio $\left(G / G_{0}, G_{0}\right.$ was initial shear modulus), and damping ratio $(\lambda)$ from small to large shear strain amplitude $\left(\gamma_{a}\right)$, are significant indexes for the seismic design and stability analysis of structures and geo-structures subjected to seismic/repeated loading. Seed et al. [3], Rollins et al. [4], and Hardin and Kalinski [5] examined the $\mathrm{G}$ and $\lambda$ of gravelly soils by cyclic triaxial tests. However, only a few tests were performed on gravel and gravelly soils due to the large size of the testing apparatus required. Lin et al. [6] pointed out that the large proportion of gravels and the unusual gap grading were the causes for the differing behavior of gravelly deposits. Tanaka [7] found that the $G / G_{0}-\gamma_{a}$ relation of an undisturbed soil could be approximately described by that of the reconstituted soil sample. Araei et al. [8] believed that the dynamic characteristics of reconstituted gravelly soils were significantly affected by gravel content, confining pressure, and loading frequency. Wang et al. [9] further indicated that the dynamic soil properties showed significant changes when VBP was higher than $30 \%$. Alhassan and VandenBerge [10] proposed a better distinguish between the behavior of 


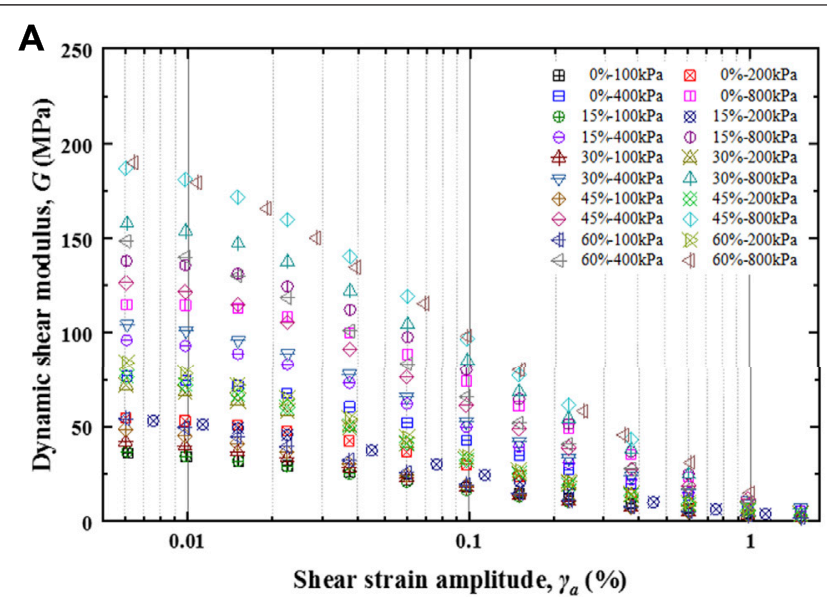

FIGURE 1 | $G$ and $\lambda$ of SRM with different VBPs and CPs.

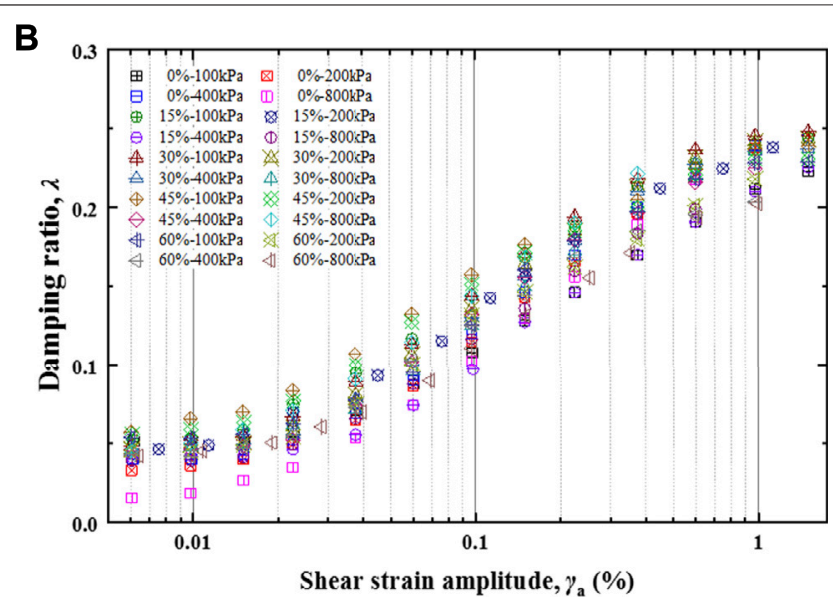

compacted sand and gravel soils in normalized dynamic shear modulus and damping ratio with shear strain. Zhang et al. [11] studied the dynamic properties and damage evolution of silty soils with different volumetric block proportions (VBPs). Xu et al. [12] investigated the dynamic properties of sand-gravel mixtures with varying contents of gravel, loading cycles, and loading frequencies. Ye et al. [13] summarized the empirical models of dynamic shear modulus and the range of reduction curves for coarse-grained soils. It is not a stretch to infer that VBPs will significantly affect the dynamic properties of SRM. This study conducted undrained cyclic triaxial tests on SRM with different VBPs and confining pressures (CPs) to investigate their dynamic characteristic evolution. The relationships of $G$ and $\lambda$ with shear strain amplitude $\left(\gamma_{a}\right)$ were discussed in detail.

\section{EXPERIMENTS}

The Large-Scale Cyclic Triaxial System (GCTS HCA-300) was used to study the dynamic behavior of SRM. SRM samples were prepared with fine-grained soil and rock blocks. The fine-grained soil with particle size less than $2 \mathrm{~mm}$ was a residual soil formed in Quaternary, collected at Nanjing Tech University's campus. The dry density of this soil was $1.63 \mathrm{~g} / \mathrm{cm}^{3}$. The natural water content was $21.58 \%$. The maximum dry density was $1.91 \mathrm{~g} / \mathrm{cm}^{3}$, and the optimum moisture content was $12 \%$. Considering that the sizes of cylindrical samples were $100 \mathrm{~mm}$ in diameter and $200 \mathrm{~mm}$ in height, the maximum diameter of rock blocks was limited to $20 \mathrm{~mm}$ to avoid the size effect. The natural density of dry rock blocks with particle sizes ranging from 2 to $20 \mathrm{~mm}$ was $2.36 \mathrm{~g} /$ $\mathrm{cm}^{3}$. Since the aerial phenomenon of rock blocks would result in significant difficulties in packing SRM samples into the mold when VBP was higher than $60 \%$, only five VBP $(0 / 15 / 30 / 45 / 60$, $\%)$ combined with four CP $(100 / 200 / 400 / 800, \mathrm{kPa})$ were considered in undrained cyclic triaxial tests. Given the water absorption of rock blocks, the extra $5 \%$ of water was mixed into SRM to avoid rock blocks absorbing water from the fine-grained soil. When SRM specimens were ready, they were saturated by a vacuum extractor until Skempton's B achieved 0.95. The axial strain amplitude during loading process increased from $1 \times 10^{-5}$ to $1 \times 10^{-2}$ level by level. The specimen was reconsolidated at the same confining pressure for $15 \mathrm{~min}$ at least to achieve an effective pore water pressure dissipation as each strain loading level ended. The loading frequency was $0.5 \mathrm{~Hz}$, and the loading cycle was 5 .

\section{RESULTS AND DISCUSSION}

Figure 1A shows the $G$ of SRM with different VBPs and CPs. The $\mathrm{G}$ of SRM exhibits degradation with $\gamma_{a}$ on the whole. High CP always results in larger $G$ values for SRM with the same VBP. The more significant deviation in $\mathrm{CP}$, the more tremendous difference in the $G$ of SRM. The $G$ of SRM at low CP illustrates a slight discrepancy of $G$ regardless of VBP. However, when CP increases, the difference in the $G$ of SRM increases with VBP. These variations should be due to specimens' compaction. High VBP may cause significant overhead phenomena in SRM. The higher CP can compact SRM specimens effectively, thereby resulting in denser structures with higher stiffness. The $G_{0}$ shows that both VBP and CP can positively impact soils' fundamental stiffness.

Figure 1B shows the $\lambda$ of SRM with different VBPs and CPs. The $\lambda$ of SRM increases with $\gamma_{a}$ and shows a zonal distribution on the whole. The whole growth process of $\lambda$ can divide into the initial stage $\left(\gamma_{a}<0.01 \%\right)$, the growth stage $\left(0.01 \% \leq \gamma_{a} \leq 1.0 \%\right)$, and the stable stage $\left(\gamma_{a}>1.0 \%\right)$. High VBP always results in $\lambda$ growing earlier in the initial stage. The growth rate of $\lambda$ is approximately the same at the growth stage, no matter what VBP is. Results of SRM with the same VBP show that high CP can narrow the distribution of $\lambda$.

Figure 2A presents the envelope curves of $G / G_{0}$ of SRM with different VBP and $\mathrm{CP}$, which exhibits a similar behavior identified by previous researchers. The $G / G_{0}$ falls within a relatively narrow band at the $\gamma_{a}$ of $5 \times 10^{-4} \%$ but has almost no effect on the curve shape of $G / G_{0}$ in $\gamma_{a}$ less than the order of $10^{-4} \%$. In 1972, Hardin and Drnevich [14] proposed a hyperbolic shear modulus reduction function for soils. Darendeli [15] 

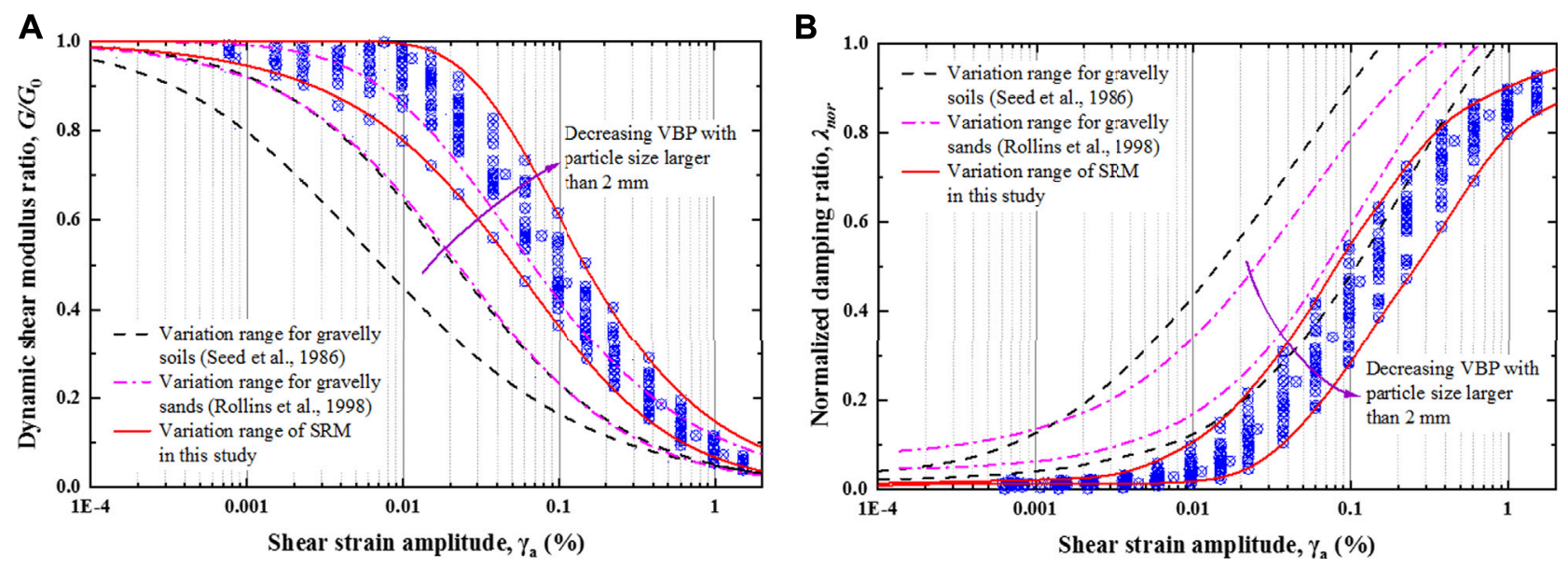

FIGURE 2 | Envelope curves of $G / G_{0}$ and $\lambda$ of SRM with different VBPs and CPs.

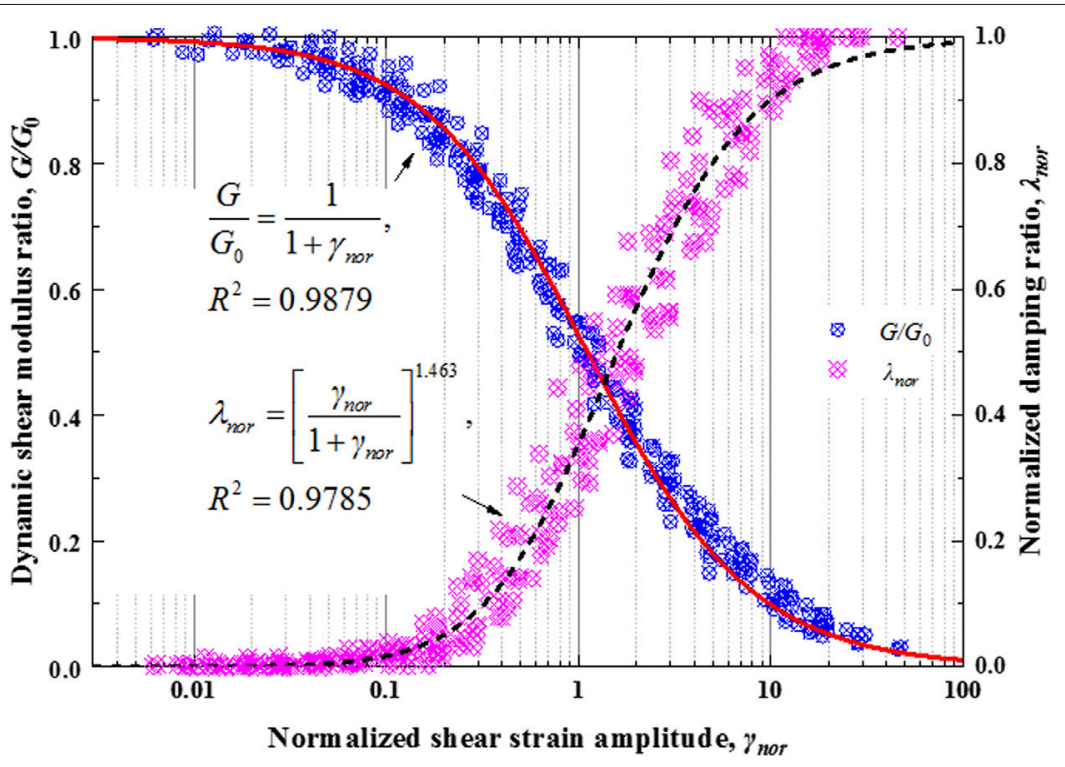

FIGURE 3 | G/Go and normalized $\lambda$ of SRM with $\gamma_{\text {nor }}$

further proposed a modified hyperbolic model based on testing of sand and gravel samples as

$$
G / G_{0}=1 /\left(1+\left(\gamma_{a} / \gamma_{r}\right)^{\alpha}\right),
$$

where $\gamma_{r}$ is the reference shear strain and is determined as the shear strain when $G / G_{0}=0.5 ; \alpha$ is the regression parameter. The $G / G_{0}$ of SRM thus can be characterized by following this hyperbolic model. It can also be found that when VBP in SRM is higher than $45 \%$, the $G / G_{0}$ curve begins to overlap with the bounds proposed by Rollins et al. [4]. When VBP in SRM is less than $45 \%$, the $G / G_{0}$ curve almost does not overlap anymore, especially in $\gamma_{a}$ between 0.01 and $0.1 \%$. Seed et al. [3] indicated that the curve characteristics of $G / G_{0}$ for natural gravel deposits with VBP of $92 \%$ at least were similar to that of sandy soil but gentler. This find also highlights that the envelope curves of $G / G_{0}$ for gravelly soils are below that of SRM.

Figure 2B shows the envelope curves of normalized $\lambda\left(\lambda_{\text {nor }}\right)$ of SRM with different VBP and CP, following the empirical model proposed by Chen et al. [16].

$$
\lambda_{\text {nor }}=\lambda_{0}\left(1-G / G_{0}\right)^{\beta} /\left(\lambda_{\max }-\lambda_{\min }\right),
$$

where $\lambda_{\min }$ and $\lambda_{\max }$ are the minimum and maximum damping ratios, $\lambda_{0}$ and $\beta$ are regression parameters related to soil properties. Similarly, the variation of $\lambda_{\text {nor }}$ falls within a relatively narrow band at the $\gamma_{a}$ of $5 \times 10^{-3} \%$ and has almost no effect on the shape of $\lambda_{\text {nor }}$ with $\gamma_{a}<10^{-3} \%$. The reason why the envelope curves of $\lambda_{\text {nor }}$ for SRM is lower than gravelly soils examined by Seed et al. [3] and Rollins et al. [4] may be that the 
soil with high VBP is harder to compact but more likely to form a loose structure in low CP when subjected to cyclic loadings, thereby resulting in a faster increase of $\lambda_{\text {nor }}$.

Figure 3 illustrates the $G / G_{0}$ and $\lambda_{\text {nor }}$ of SRM with normalized shear strain amplitude $\left(\gamma_{\text {nor }}=\gamma_{a} / \gamma_{r}\right)$. Both of them are falling within the relatively narrow bands. Namely, the $G / G_{0}$ and $\lambda_{\text {nor }}$ of SRM with $\gamma_{\text {nor }}$ are not sensitive to VBP and CP. According to the modified hyperbolic model as Eq. 1 proposed by Darendeli [15], the nonlinear relationship of $G / G_{0}$ with $\gamma_{\text {nor }}$ for SRM was fitted. It can be found that this modified hyperbolic model is also appropriate to SRM with an excellent correlation coefficient up to 0.9879 .

Taking Eq. 1 into Eq. 2 yields the following:

$$
\lambda_{\text {nor }}=\left[\gamma_{\text {nor }}^{\alpha} /\left(1+\gamma_{\text {nor }}^{\alpha}\right)\right]^{\beta} \text {. }
$$

The fitting result of $\lambda_{\text {nor }}$ shows that it has a high correlation of 0.9789 with $\gamma_{\text {nor }}$. So the empirical correlation can also be used to characterize the changes in the $\lambda$ of SRM under cyclic loadings.

\section{CONCLUSION}

Cyclic triaxial tests were conducted to understand the dynamic properties of SRM further. Outcomes indicate that both VBP and $\mathrm{CP}$ can positively impact the fundamental stiffness $\left(G_{0}\right)$ and $\lambda$ of SRM. High VBP in coarse-grained soils is more likely to result in a gentler reduction in $G / G_{0}$ and a faster increase of $\lambda_{\text {nor }}$. Both $G / G_{0}$ and $\lambda_{\text {nor }}$ of SRM can be evaluated by functions of $\gamma_{\text {nor }}$ regardless of

\section{REFERENCES}

1. Wang H, Cui Y, Lamas-Lopez F, Dupla J, Canou J, Calon N, et al. Effects of Inclusion Contents on the Resilient Modulus and Damping Ratio of Unsaturated Track-Bed Materials. Can Geotechnical J (2017) 54(12): 1672-81. doi:10.1139/cgj-2016-0673

2. Wang S, Li Y, Gao X, Xue Q, Zhang P, and Wu Z. Influence of Volumetric Block Proportion on Mechanical Properties of Virtual Soil-Rock Mixtures. Eng Geology (2020) 278:105850. doi:10.1016/j.enggeo.2020.105850

3. Seed HB, Wong RT, Idriss IM, and Tokimatsu K. Moduli and Damping Factors for Dynamic Analyses of Cohesionless Soils. J geotechnical Eng (1986) 112(11):1016-32. doi:10.1061/(asce)0733-9410(1986)112:11(1016)

4. Rollins KM, Evans MD, Diehl NB, and Daily WD, III. Shear Modulus and Damping Relationships for Gravels. J Geotechnical Geoenvironmental Eng (1998) 124(5):396-405. doi:10.1061/(asce)1090-0241(1998)124:5(396)

5. Hardin BO, and Kalinski ME. Estimating the Shear Modulus of Gravelly Soils. J Geotechnical Geoenvironmental Eng (2005) 131(7):867-75. doi:10.1061/ (ASCE)1090-0241(2005)131:7(867)

6. Lin S, Lin PS, Luo H, and Juang CH. Shear Modulus and Damping Ratio Characteristics of Gravelly Deposits. Can Geotechnical J (2000) 37(3):638-51. doi:10.1139/t99-133

7. Tanaka Y. Evaluation of Undrained Cyclic Strength of Gravelly Soil by Shear Modulus. Soils and Foundations (2003) 43(4):149-60. doi:10.3208/sandf.43.4_149

8. Araei AA, Razeghi HR, Tabatabaei SH, and Ghalandarzadeh A. Dynamic Properties of Gravelly Materials. Scientia Iranica (2010) 17(4):245-61.

9. Wang Y, Li X, and Zheng B. Stress-strain Behavior of Soil-Rock Mixture at Medium Strain Rates - Response to Seismic Dynamic Loading. Soil Dyn Earthquake Eng (2017) 93:7-17. doi:10.1016/j.soildyn.2016.10.020

10. Alhassan MM, and VandenBerge DR. Shear Modulus and Damping Relationships for Dynamic Analysis of Compacted Backfill Soils. Innovative Infrastructure Solutions (2018) 3:43. doi:10.1007/s41062-018-0152-5

11. Zhang D, Li Q, Liu E, Liu X, Zhang G, and Song B. Dynamic Properties of Frozen Silty Soils with Different Coarse-Grained Contents Subjected to Cyclic
VBP and CP. This study's results can provide a valuable reference to understand the dynamic response characteristics and energy dissipation mechanisms of SRM and other similar geo-materials.

\section{DATA AVAILABILITY STATEMENT}

The original contributions presented in the study are included in the article/Supplementary Material; further inquiries can be directed to the corresponding authors.

\section{AUTHOR CONTRIBUTIONS}

Funding acquisition and formal writing of the work, SW and XG; investigation and data analysis of the work, $\mathrm{HH}$; review and editing of the work, WM, CS, and PZ. All authors have read and agreed to the published version of the manuscript.

\section{FUNDING}

This work was supported by the National Natural Science Foundation of China (No. 41902282), the Natural Science Foundation of Jiangsu Province (No. BK20171006), and the State Key Laboratory of Frozen Soil Engineering (No. SKLFSE201809).

Triaxial Loading. Cold Regions Sci Technol (2019) 157:64-85. doi:10.1016/ j.coldregions.2018.09.010

12. Xu D, Liu H, Rui R, and Gao Y. Cyclic and Postcyclic Simple Shear Behavior of Binary Sand-Gravel Mixtures with Various Gravel Contents. Soil Dyn Earthquake Eng (2019) 123:230-41. doi:10.1016/j.soildyn.2019.04.030

13. Ye Y, Cai D, Yao J, Wei S, Yan H, and Chen F. Review on Dynamic Modulus of Coarse-Grained Soil Filling for High-Speed Railway Subgrade. Transportation Geotechnics (2021) 27:100421. doi:10.1016/j.trgeo.2020.100421

14. Hardin BO, and Drnevich VP. Shear Modulus and Damping in Soils: Design Equations and Curves. J Soil Mech Foundations Div (1972) 98:667-92. doi:10.1061/jsfeaq.0001760

15. Darendeli MB. Development of a new family of normalized modulus reduction and material damping curves. Texas: University of Texas at Austin (2011).

16. Chen G, Zhou Z, Sun T, Wu Q, Xu L, Khoshnevisan S, et al. Shear Modulus and Damping Ratio of Sand-Gravel Mixtures over a Wide Strain Range. J earthquake Eng (2019) 23(8):1407-40. doi:10.1080/13632469.2017.1387200

Conflict of Interest: The authors declare that the research was conducted in the absence of any commercial or financial relationships that could be construed as a potential conflict of interest.

Publisher's Note: All claims expressed in this article are solely those of the authors and do not necessarily represent those of their affiliated organizations, or those of the publisher, the editors and the reviewers. Any product that may be evaluated in this article, or claim that may be made by its manufacturer, is not guaranteed or endorsed by the publisher.

Copyright (C) 2021 Wang, Gao, Hui, Ma, Shi and Zhang. This is an open-access article distributed under the terms of the Creative Commons Attribution License (CC BY). The use, distribution or reproduction in other forums is permitted, provided the original author(s) and the copyright owner(s) are credited and that the original publication in this journal is cited, in accordance with accepted academic practice. No use, distribution or reproduction is permitted which does not comply with these terms. 